Article

\title{
Expression of Oncogenic Drivers in 3D Cell Culture Depends on Nuclear ATP Synthesis by NUDT5
}

\author{
Katherine E. Pickup ${ }^{1}{ }^{(0}$, Felicitas Pardow ${ }^{1}{ }^{\circledR}$, José Carbonell-Caballero ${ }^{1}$, Antonios Lioutas ${ }^{1}{ }^{(\mathbb{O}}$, \\ José Luis Villanueva-Cañas ${ }^{1}\left(\mathbb{D}\right.$, Roni H. G. Wright ${ }^{1, *(\mathbb{D})}$ and Miguel Beato ${ }^{1,2, *}$ \\ 1 Gene Regulation, Stem Cells and Cancer Program, Centre for Genomic Regulation (CRG), The Barcelona \\ Institute of Science and Technology (BIST), Dr. Aiguader 88, 08003 Barcelona, Spain \\ 2 Department of Life Science, Universitat Pompeu Fabra (UPF), 08003 Barcelona, Spain \\ * Correspondence: roni.wright@crg.es (R.H.G.W.); miguel.beato@crg.es (M.B.)
}

Received: 31 July 2019; Accepted: 4 September 2019; Published: 10 September 2019

check for updates

\begin{abstract}
The growth of cancer cells as oncospheres in three-dimensional (3D) culture provides a robust cell model for understanding cancer progression, as well as for early drug discovery and validation. We have previously described a novel pathway in breast cancer cells, whereby ADP (Adenosine diphosphate)-ribose derived from hydrolysis of poly (ADP-Ribose) and pyrophosphate (PPi) are converted to ATP, catalysed by the enzyme NUDT5 (nucleotide diphosphate hydrolase type 5). Overexpression of the NUDT5 gene in breast and other cancer types is associated with poor prognosis, increased risk of recurrence and metastasis. In order to understand the role of NUDT5 in cancer cell growth, we performed phenotypic and global expression analysis in breast cancer cells grown as oncospheres. Comparison of two-dimensional (2D) versus 3D cancer cell cultures from different tissues of origin suggest that NUDT5 increases the aggressiveness of the disease via the modulation of several key driver genes, including ubiquitin specific peptidase 22 (USP22), RAB35B, focadhesin (FOCAD) and prostagladin E synthase (PTGES). NUDT5 functions as a master regulator of key oncogenic pathways and of genes involved in cell adhesion, cancer stem cell (CSC) maintenance and epithelial to mesenchyme transition (EMT). Inhibiting the enzymatic activities of NUDT5 prevents oncosphere formation and precludes the activation of cancer driver genes. These findings highlight NUDT5 as an upstream regulator of tumour drivers and may provide a biomarker for cancer stratification, as well as a novel target for drug discovery for combinatorial drug regimens for the treatment of aggressive cancer types and metastasis.
\end{abstract}

Keywords: breast cancer; proliferation; oncospheres; cell-cell communication; cytoskeleton; motility; recurrence; cancer stem cell (CSC), metastasis; 3D cell cultures; EMT

\section{Introduction}

Metastasis is the main cause of death for breast cancer patients. Metastases are routinely aggressively treated with surgery, followed by chemo- and/or radiotherapy, as few targeted drug regimens are available for metastatic treatment [1]. In order to provide novel targets for drug development, a more complete understanding of the mechanisms, gene expression changes and key regulators involved within the process of metastasis is key. The progression of metastasis can be split into several distinct stages: local proliferation of the primary tumour, local invasion and intravasation (epithelial to mesenchyme transition (EMT)), dissemination and extravasion and finally, colonisation and proliferation within the secondary site. Each stage of the process is dependent on nuclear and gene expression reorganisation to activate or repress specific pathways at each stage [1].

Pluripotent cancer stem cells (CSC) have been identified in the majority of solid and hematologic cancers and have been shown in numerous studies to be the initiators of tumour development, 
proliferation, metastatic dissemination and colonisation [2]. CSCs are low in number within the primary tumour, however, because of their self-renewal capacities, they have been shown to be resistant both to chemo- and radiotherapy [3,4]. Indeed, several studies have indicated that these kinds of treatments actually promote "stemness", which may explain why recurrent tumours are often more aggressive than the primary [5]. Stemness involves EMT, whereby the gene expression and phenotypic characteristics of the epithelial cells are changed, increasing the cell capacity for migration, invasion and an avoidance of apoptosis.

We have previously identified NUDIX5 (nucleotide diphosphate linked to moiety-X 5), more generally referred to as NUDT5 (nucleotide diphosphate hydrolase type 5), as a key regulator in hormone receptor positive and serum-starved breast cancer cells exposed to hormone. In response to hormones, PARP1 (poly-ADP-ribose polymerase 1) is activated by CDK2-mediated phosphorylation within the $\mathrm{NAD}^{+}$binding cleft [6] that results in a more open catalytic domain, increasing the activity of the enzyme [7]. Activated PARP1 then rapidly generates poly-ADP-ribose (PAR) from NAD ${ }^{+}$ synthesized within the cell nucleus by NMNAT1 (Nicotinamide Nucleotide Adenylyltransferase 1) within the nucleus of breast cancer cells. The main acceptor for PAR is PARP1 itself, followed by core and linker histones. This massive PARylation gives rise to a more open chromatin structure, aiding the recruitment of chromatin remodelling complexes and the transcription machinery to hormone regulated genes whereby the activated progesterone receptor (PR) binds the following hormone. This massive generation of PAR is transient in nature because of the activity of the counteracting nuclear enzyme, PARG (poly-ADP-ribose glycohydrolase), which cleaves PAR into single ADP-ribose (ADPR) units. This balance of PARP1 and PARG enzymatic activities is essential to ensure that the metabolic substrates required for PAR synthesis, namely ATP and $\mathrm{NAD}^{+}$, are not exhausted to prevent cell death by parthanatos [8]. The importance of parthanatos avoidance and the consequently tight regulated balance of PARG and PARP1 enzymatic activities is found in many other biological situations in mammalian cells, not only in hormone induction, but also including DNA damage [9], replication [10] and cell cycle, chromatin remodelling and gene expression [11].

NUDT5 is a homodimer (Protein Databank; PDB ID:2DSC [12]) that was identified by mass spectroscopy as an interactor of PAR following hormones [13]. Subsequently, we found that NUDT5 not only hydrolyses ADP-ribose (ADPR) to AMP and ribose-5-phosphate (R5P), but in the presence of pyrophosphate (PPi) can also act as a pyrophosphorylase, generating ATP and R5P [13]. This later reaction requires the dephosphorylation of NUDT5 at T45, destabilizing the homodimer and opening the substrate binding groove to enable PPi entry [13].

NUDT5 is overexpressed in breast cancer compared to normal tissue and stratifying patients on the basis that elevated expression levels of NUDT5 predicts a poorer prognosis for patients [13]. However, the mechanism by which NUDT5 drives cancer progression and is exploited by cancer cells is not known. In this article, we focus on identifying NUDT5-dependent pathways in cancer progression and metastasis. To this end, we used as an experimental model the generation and maintenance of oncospheres starting from breast cancer cells. These structures can be generated with multiple cancer cell lines and are known to be enriched in CSCs, on the basis of the expression of CSC genes, including ALDH1, SOX2, CD44+/CD24- [14,15]. They are also enriched in markers of EMT, including CTNNB1, EGR1, ERBB2 and MUC1 [16,17]. Thus, compared to cells in two-dimensional (2D) culture conditions, oncospheres provide a more realistic model for understanding cancer progression in vivo [18], and are appropriate for performing early stage cancer drug discovery validation and optimisation [19]. The data presented here may aid in the development of more targeted therapies for cancer patients with advanced disease. 


\section{Results and Discussion}

\subsection{NUDT5 in Cancer}

\subsubsection{NUDT5 in Expression in Human Cancers Correlates with an Aggressive Phenotype}

Analysis of the TGCA data revealed that NUDT5 mRNA levels were elevated in tumours compared to normal tissue across the spectrum of cancer types (Figure S1A, abbreviations of cancer types; Table S1). A positive staining of NUDT5 was also found within several cancer types of different origin; indeed over $40 \%$ of liver and $30 \%$ of breast cancers show a positive staining with an antibody specific for NUDT5 (Figure S1B). Immuno-histological staining of NUDT5 in patient tumour samples and normal samples showed a clear increase in tumour versus normal tissues (Figure S1C), with metadata for the samples given in Table S2. Complementary to the observation that NUDT5 can be used as a prognostic marker in breast cancer [13] elevated NUDT5 levels were also prognostic in kidney, adrenal, brain and liver patient datasets (Figure S1D-I). Moreover, breast cancer patients with increased expression of NUDT5 showed an enhanced at risk of recurrence and metastasis (Figure S1J). Collectively, these findings led us to the hypothesis that elevated levels of NUDT5 were prognostic of a poor outcome due to the development of a more aggressive cancer disease phenotype.

\subsubsection{Effect of Nudt5 Knockdown on Cell Growth in 2D Cultures, Cell Migration and Colony} Formation Assays

To ascertain whether NUDT5 is indeed driving a more aggressive cancer phenotype, we generated T47D breast cancer cells stably depleted of NUDT5, as well as the corresponding rescue cell lines. First, we used a Tet-Off system and specific shRNAs to generate stable cell lines, wherein the endogenous NUDT5 was over 95\% depleted (NUDT5 ${ }^{\mathrm{KD}}$ ) (Figure $1 \mathrm{~A}-\mathrm{C}$ and Figure S1K). Using NUDT5 ${ }^{\mathrm{KD}}$ cells and a pKAR plasmid [20] containing the Tet-Off driving, an shRNA resistant FLAG-tagged NUDT5 mutant rescue cell line was generated (NUDT5 $\left.{ }^{\mathrm{RES}}\right)$. An efficient rescue was reproducibly observed across several stable clones at both the protein and mRNA levels (Figure 1B-D).
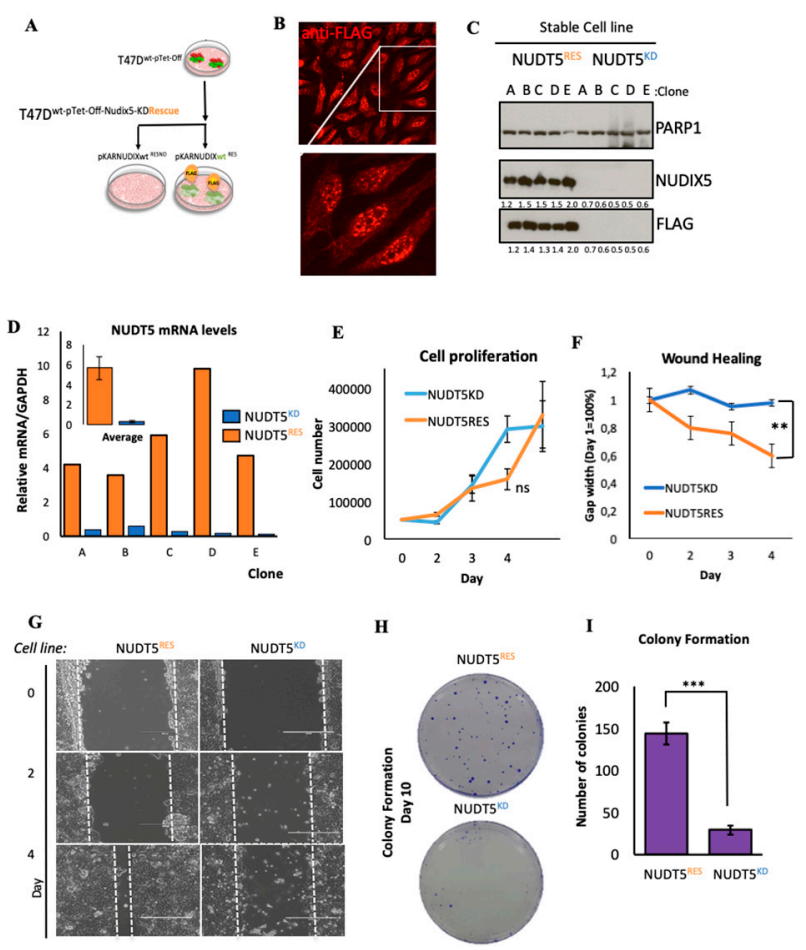

I Colony formation

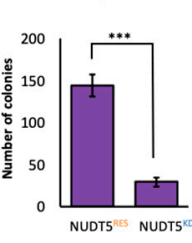


Figure 1. Characterisation of NUDT5 $5^{\mathrm{KD}}$ and $\mathrm{NUDT} 5^{\mathrm{RES}}$ cell lines in $2 \mathrm{D}$ cell culture. (A) Experimental approach for the stable knockdown and inducible pKAR rescue of NUDT5 (nucleotide diphosphate hydrolase type 5) in T47D ${ }^{\mathrm{M}}$ cells. Protein expression of FLAG-NUDT5 using anti-FLAG antibodies in $\mathrm{T}_{47 D}{ }^{\mathrm{M}}$ cells depleted of NUDT5 (NUDT5 ${ }^{\mathrm{KD}}$ ) or rescued with the stable expression of the wild type FLAG-NUDT5 (NUDT5 ${ }^{\text {RES }}$ ) visualised by immunofluorescence (B) and by western blotting (C) (PARP1 (poly-ADP-ribose polymerase 1) is shown as a loading control) in several clonal cell lines. Intensity ratio of the observed bands NUDT5 and FLAG are standardised against PARP1 and the values shown below. The full western blot is shown in Figure S1K. (D) Relative mRNA expression (normalised against GAPDH) of NUDT5 in NUDT5 ${ }^{\mathrm{KD}}$ and NUDT5 ${ }^{\mathrm{RES}}$ cell lines for each clonal cell line. The inset shows the average of all clones. (E) Cell proliferation assays measured by BrdU incorporation in NUDT5 KD and NUDT5 ${ }^{\text {RES }}$ cell lines. (F) Quantification of cell migration assays in NUDT5 ${ }^{\mathrm{KD}}$ versus NUDT5 ${ }^{\mathrm{RES}}$ cell lines. (G) Representative images of cell migration assays at different time points, NUDT5 ${ }^{\mathrm{KD}}$ versus NUDT5 ${ }^{\text {RES }}$ cell lines. (H) Colony formation assay with NUDT5 ${ }^{\text {KD }}$ versus NUDT5 ${ }^{\text {RES }}$ cell lines after 10 days in culture. (I) Quantification of data shown in (H), showing a statistically significant decrease $(p<0.01)$ in surviving colonies in the absence of NUDT5. The mean \pm SEM (standard error of the mean) of three replicas are shown.

Surprisingly, breast cancer cell proliferation was not significantly affected in NUDT5 ${ }^{\mathrm{KD}}$ cell lines when grown in 2D culture (Figure 1E). However, in wound healing and clonogenic assays, we observed a significant defect in the NUDT5 ${ }^{\mathrm{KD}}$ cell lines (Figure 1F-I), suggesting a role for NUDT5 in cancer cell motility, cell migration or on growth in low cell density conditions.

\subsubsection{Characterisation of the Expression Profile Changes in T47D Oncosphere Model}

These observations led us to consider that NUDT5 had no effect on the cell cycle under normal growth conditions but could drive changes in the cancer cell phenotype, perhaps promoting an EMT and/or stem cell-like state. One experimental model used often for understanding these processes is growing the cancer cell lines in non-adherent conditions as three-dimensional (3D) oncospheres. During this process, the majority of seeded single cells die during the initial days of culture because of the challenge of growing in non-adherent surfaces [14], and the surviving cells express markers of EMT and stemness, and initiate the formation of spheres within 5-6 days [2,15].

Therefore, we generated oncospheres in T47D NUDT5 ${ }^{\text {RES }}$ cell lines and, in order to gain a more global understanding of the gene expression changes which took place following the transition between 2D and 3D (Figure 2A), RNA-seq was carried out in NUDT5 ${ }^{\text {RES }}$ grown in the two conditions (Figure S2A-C, Table S3). A significant portion of the 5850 genes, which significantly changed their expression between 2D and 3D culture conditions (Figure 2B), were found within a curated set of 480 oncosphere-regulated genes (Figure 2C and Table S4), including genes involved in EMT, oncosphere growth, signalling, adhesion, pluripotency and stem cells [21-23] referring to the dEMT database (http://dbemt.bioinfo-minzhao.org). The most significant functional enrichment and expression changes between 2D and 3D were observed for genes involved in EMT (108 genes) (Figure 2C-D). Upregulation of several membrane proteins: EMP3, FGFR1, GHR and IGF2R, involved specifically in mammosphere growth [22] occurred, and canonical stem cell markers EPCAM and SOX2 [23] were also up-regulated during the transition from 2D to 3D (Figure 2E). 
$\mathbf{A}$

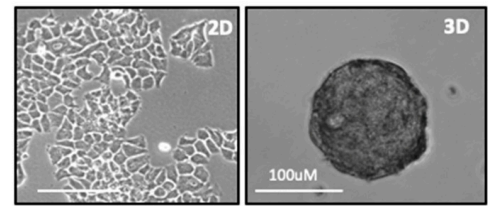

B

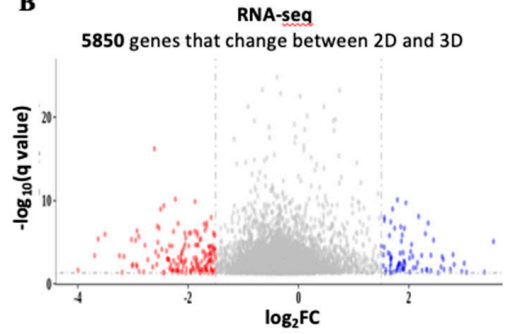

C

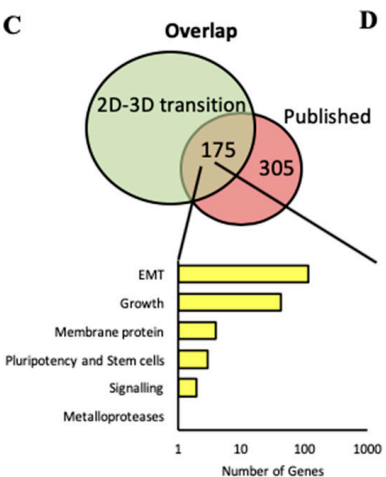

G

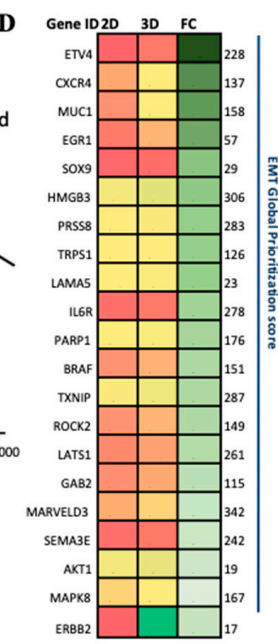

E
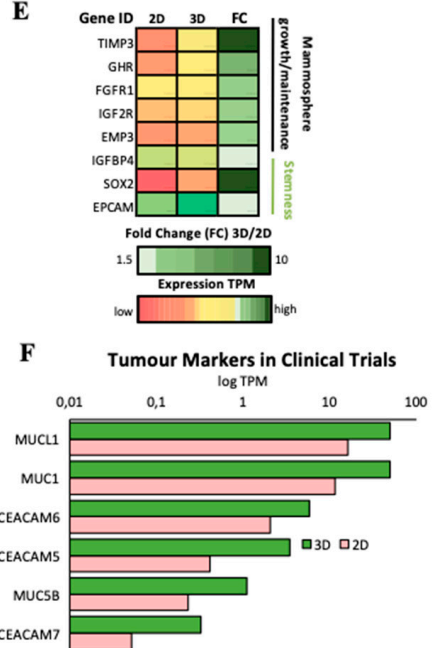

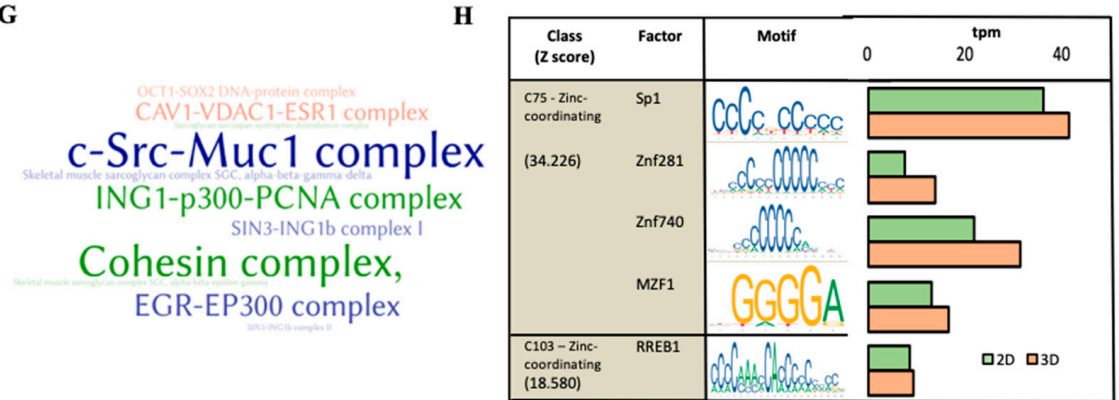

Figure 2. Analysis of the gene expression changes occurring during a transition from $2 \mathrm{D}$ to three-dimensional (3D) growth conditions. (A) Representative images of NUDT5 ${ }^{\text {RES }}$ cell lines grown in 2D and 3D culture conditions, scale bar $=100 \mu \mathrm{M}$. (B) RNA-seq differential expression analysis of NUDT5 ${ }^{\text {RES }}$ cells grown in 3D and in 2D culture conditions. Changes in gene expression were considered significant if the log fold change was higher than 1.5 (fold change $(\mathrm{FC})>1.5$ ) and the $q$-value was lower than $0.01(q<0.01)$. (C) Venn diagram showing the overlap of genes expressed differentially in 3D culture and a manually curated list of oncosphere expression datasets (Table S4). A histogram of the more enriched functional groups in the overlapping cluster of 175 genes is shown at the right margin. (D) Heat map presentation of the expression levels in genes involved in epithelial to mesenchyme transition (EMT) in cells growing in 2D and 3D conditions, ranked following the fold change (FC). The EMT Global Prioritization Score is indicated in the right margin. (E) Heat map representation of the RNA expression levels (2D and 3D) of genes involved in stemness and mammosphere growth, ranked in descending order of 3D/2D fold change (FC). (F) Expression levels of the tumour marker families carcinoembryonic antigen (CEA)-related cell adhesion molecules (CEACAM) and MUCIN in 2D and 3D RNA sequence samples. (G) Word cloud showing CORUM (comprehensive resource of mammalian protein complexes) database analysis detailing the significantly altered protein complexes in the genes altered in 2D to 3D transition. (H) Transcription factor binding site motifs (central column) enriched within promoters of genes expressed in 3D. The histogram on the right shows the expression levels of the corresponding transcription factors in cells growing in 2D (green) and 3D (orange). 
Tumour markers, including those within the carcinoembryonic antigen (CEA)-related cell adhesion molecules (CEACAM) family, have mainly been used for the diagnosis and monitoring of colon carcinoma recurrence following surgery [24], although elevated levels have also shown clinical use in cancer monitorization for several cancers, including lung, pancreatic, liver, cervical and breast cancer [25-30]. Elevated levels of CEACAM5 were found in breast cancers and were identified as a metastatic driver [31]. We found significantly elevated levels of CEACAM 5, 6 and 7 in T47D cells grown in 3D cell culture compared with 2D culture (Figure 2F). In addition, the transmembrane protein MUC1 is often overexpressed in metastatic cancers and-like CEACAM-is used to monitor metastatic progression [32,33]. MUC1 is known to upregulate the expression of EMT drivers and to reduce the contacts between cancer cells, facilitating basement membrane invasion. We found that the transmembrane proteins MUC1, MUCL1 and MUC5 showed a significant increase in expression in oncospheres compared with cells in 2D culture (Figure 2F). These findings further strengthen the oncosphere model as an appropriate model for breast cancer studies.

Furthermore, changes within the Mucin1 complex (cSRC-MUC1) were also found in comparing cells grown in 2D and 3D cultures. MUC1 co-localisation with SRC1 on the plasma membrane has been shown to be essential for SRC1 signalling in tumour development [34]. These alterations were also confirmed following CORUM (comprehensive resource of mammalian protein complexes) analysis of the changes in gene expression (Figure 2G). In addition, we found changes in Caveolin1-VDAC-ESR1 complexes, which are involved in cell-cell communication, membrane mobilisation and cell adhesion (Figure 2G), and in complexes regulating transcription, chromosome organisation and nuclear architecture from 2D to 3D, including the cohesin complex, SIN3-ING1b complex 1 and II, ING-p300-PCNA and EGR-EP300 complexes (Figure 2G and Table S5), in addition to alterations effecting the stem cell transcription factor complexes OCT1-SOX2, PAX6-SOX2 and OCT4-SOX2. Gene ontology and pathway enrichment showed a significant alteration in key regulatory processes, including mitosis, cell cycle, DNA repair, and chromatin cohesion (Figure S2D,E and Tables S6-S8). Analysis of the transcription binding site motifs enriched within promoters ( $1.5 \mathrm{kbp}$ up- and downstream of the TSS (Transcription start site) of genes involved in the transition between 2D and 3D showed a significant enrichment in SP1, ZNF281, ZNF740, MZF1 and RREB1 motifs, wherein not only were the binding sites enriched, but the expression of the transcription factors was also increased at the RNA level from 2D to 3D (Figure $2 \mathrm{H}$ and Table S9), suggesting a system-wide reorganisation of the expression program. Notably, SP1 and ZNF281 were predictive of a poor outcome on the basis of our analysis of publically available patient datasets (Figure S2F,G) and previous observations [30,35]; MZF1 is a known oncogenic transcription factor involved in tumour progression [36,37]. Overall the overlap with previously published datasets, as well as the enrichment in functions associated with a more stem-like phenotype and clinical tumour markers during the transition from 2D to 3D, validates the oncosphere model as a representation of a more CSC-like phenotype.

\subsubsection{NUDT5 Knock-Down Prevents Oncosphere Formation}

Unlike NUDT5 ${ }^{\mathrm{RES}}$ cells, NUDT5 ${ }^{\mathrm{KD}}$ cells cannot form oncospheres (Figure 3A). Indeed the "structures" that remain after 5 days are smaller, less abundant and lose their spherical appearance (Figure 3A-C). NUDT ${ }^{\text {RES }}$ oncospheres show no phenotypic changes compared to T47D wild type cells (Figure S3A). As expected, NUDT $5^{\mathrm{RES}}$ oncospheres, but not $\mathrm{NUDT} 5^{\mathrm{KD}}$, were enriched in cells expressing cancer stem cell (CSC) markers, as exemplified by the $C D 44+/ C D 24-$ ratio that was also low in cells growing in 2D cultures (Figure 3D), the alcohol dehydrogenase levels (ALDH1, Figure 3E) and the cell adhesion proteins including caveolin (CAV1, Figure S3B). Moreover, the self-renewal pluripotent capacity of the oncospheres derived from NUDT5 ${ }^{\mathrm{RES}}$ cells was significantly higher than those for NUDT5 ${ }^{\mathrm{KD}}$ cells (Figure 3F). These findings suggest that the enriched CSC phenotype within oncospheres was dependent on the expression of NUDT5. 


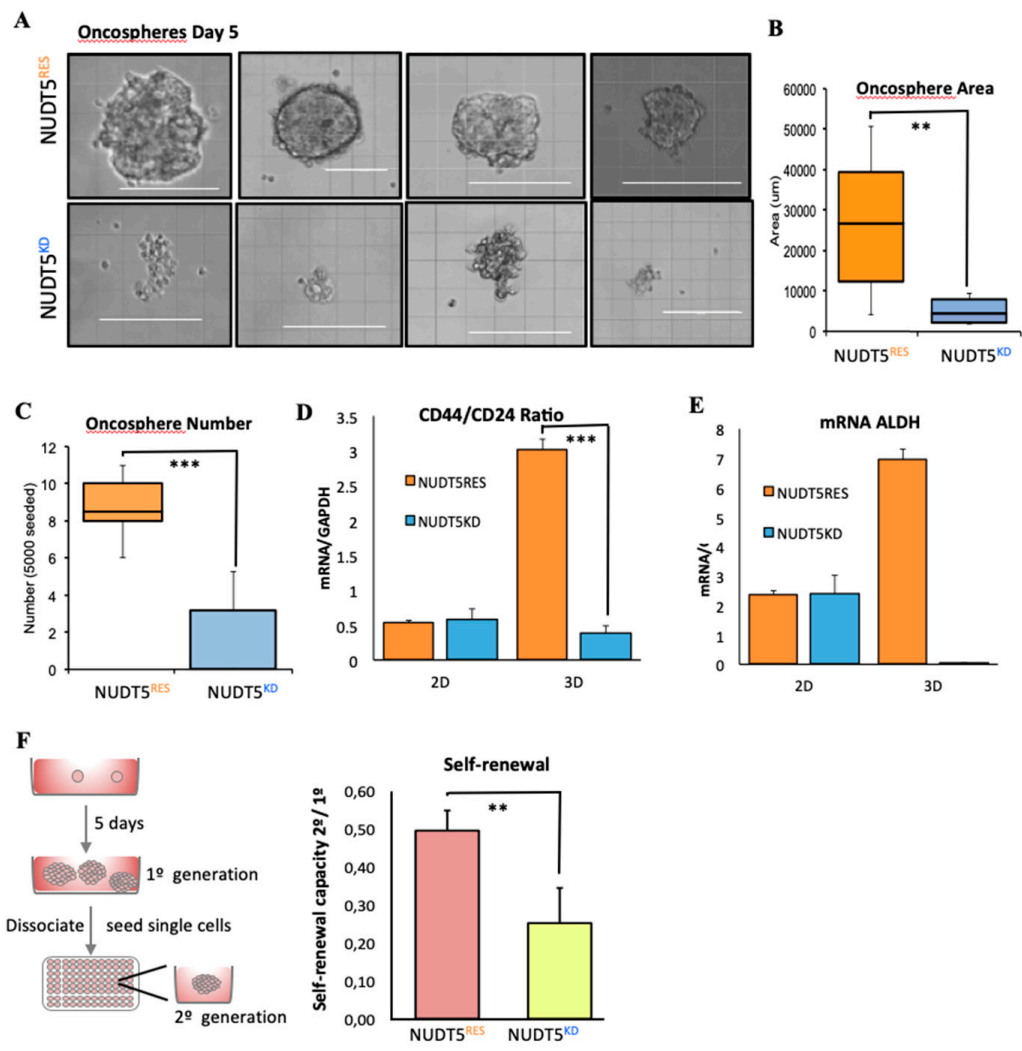

Figure 3. NUDT5 is essential for oncosphere growth and maintenance. (A) Bright field images of oncospheres formed following 5 days in culture in $\mathrm{NUDT} 5^{\mathrm{KD}}$ or NUDT5 ${ }^{\mathrm{RES}}$ cell lines. Scale bar represents $200 \mu \mathrm{M}$. (B) Quantification of the area of oncospheres formed by NUDT5 ${ }^{\mathrm{KD}}$ or NUDT5 ${ }^{\mathrm{RES}}$ cell lines mean \pm SEM. (C) Quantification of the number of oncospheres formed in NUDT5 ${ }^{\mathrm{KD}}$ or NUDT5 ${ }^{\mathrm{RES}}$ cell lines, mean \pm SEM. (D) CD44 and CD24 ratio in NUDT5 ${ }^{\mathrm{KD}}$ or NUDT5 ${ }^{\mathrm{RES}}$ cell lines, grown in 2D and 3D; mean \pm SEM. (E) ALDH1 mRNA levels ratio in NUDT5 ${ }^{\mathrm{KD}}$ or NUDT5 ${ }^{\mathrm{RES}}$ cell lines, grown in 2D and 3D; mean \pm SEM. (F) Self-renewal capacity of second generation oncospheres in $\mathrm{NUDT}^{\mathrm{KD}}$ or NUDT5 ${ }^{\mathrm{RES}}$ cell lines; mean \pm SEM.

2.1.5. NUDT5 Promotes the Expression of Genes Involved in EMT and in the Aggressive Tumour Phenotype

In order to understand the role of NUDT5 in the characteristic changes in gene expression observed in T47D cells grown in 3D culture conditions, we carried out RNA-seq analysis in NUDT5 ${ }^{\text {RES }}$ versus 3D NUDT5 ${ }^{\mathrm{KD}}$ grown in 3D conditions. Neither NUDT5 mRNA nor protein levels changed during in 3D conditions relative to $2 \mathrm{D}$ conditions (Figure $4 \mathrm{~A}$ and Figure S3C). However, a comparison of NUDT5 ${ }^{\mathrm{RES}}$ versus NUDT $5{ }^{\mathrm{KD}}$ both in 3D conditions showed a differential expression of 128 genes (Figure 4B,C). Comparing the genes dependent on NUDT5 at both 2D (Figure S3D) and 3D cell culture conditions revealed a core of 60 genes (including NUDT5), the expression of which was dependent on NUDT5, independent of the culture conditions (Figure 4C). Closer inspection of this set of NUDT5-dependent genes revealed that expression was regulated in the same direction, and to a similar extend independent of the 2D or 3D culture condition (Figure 4D). On the basis of these findings, we considered these set of NUDT5-dependent genes to explain the inability of cancer cells to form oncospheres in the absence of NUDT5.

The comparison of RNA-seq from NUDT5 $5^{\mathrm{KD}}$ and $\mathrm{NUDT} 5^{\mathrm{RES}}$ in 3D culture conditions also revealed 68 gene, which induced only in 3D culture conditions and not in 2D conditions (Figure 4C). These set of genes were more likely candidates for explaining the need of NUDT5 for oncosphere formation. Disease terms enriched in this set of 68 genes included breast and, specifically, breast neoplasms (Figure 4C). Analysis of reactome pathways indicated that this set of genes were enriched 
in extracellular matrix organisation, Notch and Hedgehog signalling pathways (Figure 4E). The Notch signalling pathway has been shown to be involved in invasive breast cancer and key proteins within the pathway identified as targets for cancer therapy drug discovery [38], and mammosphere growth is inhibited following inhibition of Notch signalling [39]. The Hedgehog signalling pathway is involved in cell survival, cell self-renewal and CSC [40], and its aberrant expression has been observed in over $25 \%$ of cancers, including breast cancer [41]. Indeed, it has been shown for both Notch and Hedgehog that the CSC niche in mammospheres depends upon signalling via these pathways [42,43].

A

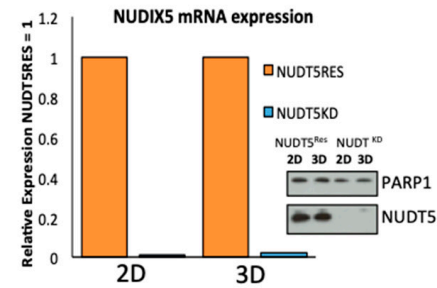

C

Differentially Expressed Genes

2 Dersus 3 D NUDT5 ${ }^{\text {Es }}$ versus NUDT5 ${ }^{\times 0}$

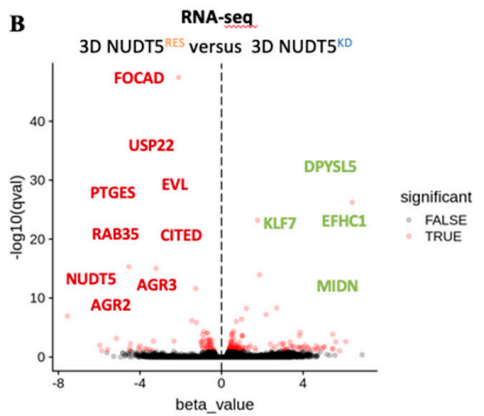

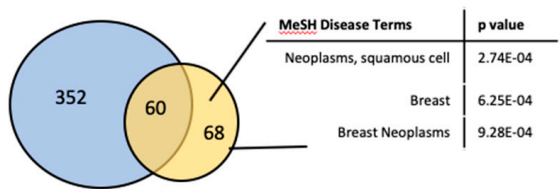

D

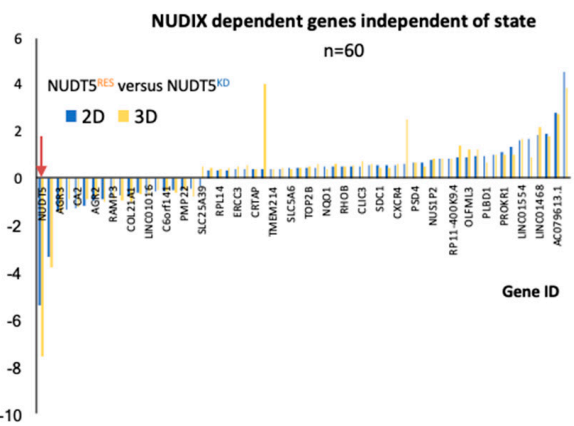

$\mathbf{E}$

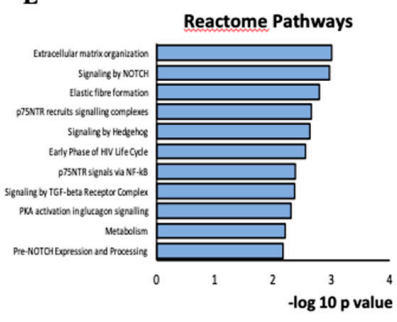

Figure 4. Gene expression changes induced specifically in 3D culture conditions depend on NUDT5. (A) Relative mRNA expression (normalised against GAPDH) of NUDT5 in NUDT5 ${ }^{\mathrm{KD}}$ and NUDT5 ${ }^{\mathrm{RES}}$ cell lines in 2D and 3D conditions, inset protein expression of NUDT5. Full western blot is found in Figure S3C. (B) Volcano plot from RNA-seq differential expression analysis comparing 3D-NUDT5KD and 3D-NUDT5 ${ }^{\text {RES }}$ cell lines. (C) Venn diagram showing the overlap between 2D and 3D analysis. Genes changed in 2D dependent on NUDT5 shown in blue (2D-NUDT5 ${ }^{\text {KD }}$ versus 2D-NUDT5 ${ }^{\text {RES }}$ ) and genes changed in 3D dependent on NUDT5 in yellow (3D-NUDT5 ${ }^{\mathrm{KD}}$ versus $3 \mathrm{D}-\mathrm{NUDT} 5^{\mathrm{RES}}$ ). Enriched medical disease terms (MeSH) within the 3D specific data set are shown (right panel). (D) mRNA expression of 60 genes, which were dependent on NUDT5 at both the 2D and 3D states; NUDT5 is indicated by an arrow. (E) Reactome pathway analysis showing the significantly $(p<0.05)$ enriched pathways which were dependent on NUDT5 in 3D.

\subsubsection{NUDT5-Catalysed Synthesis of Nuclear ATP is Required for Oncosphere Formation}

Enzymatically, NUDT5 has the ability to generate AMP or ATP depending on its phosphorylation status and the availability of substrates PPi [44]. Given that the gene expression data demonstrates that NUDT5 is essential for oncosphere generation, and for enrichment in gene expression signatures for CSC and tumour markers, we next used NUDT5 and to the need for NUDT5 enzymatic activity for oncosphere generation. Page and colleagues characterised the NUDT5 specific inhibitor TH5427 [45], which has been shown to block both the AMP and ATP generating activities of NUDT5. In the presence 
of TH5427, the growth of NUDT5 ${ }^{\mathrm{RES}}$ oncospheres was inhibited, showing that not only the presence of NUDT5 but also its enzymatic activity is required for oncosphere generation (Figure 5A-C).

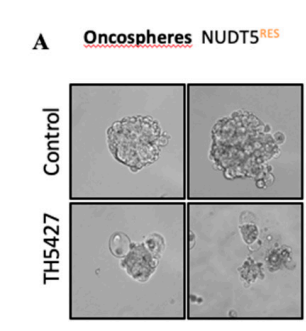

D

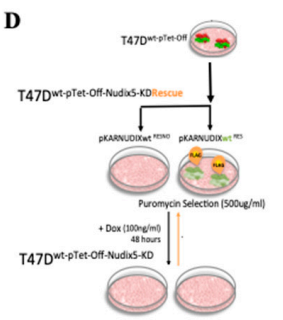

G
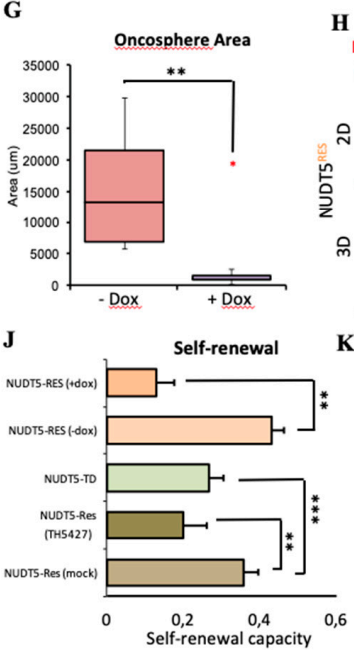

$\mathbf{H}$

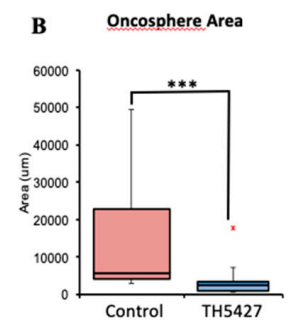

$$
\mathbf{E}
$$
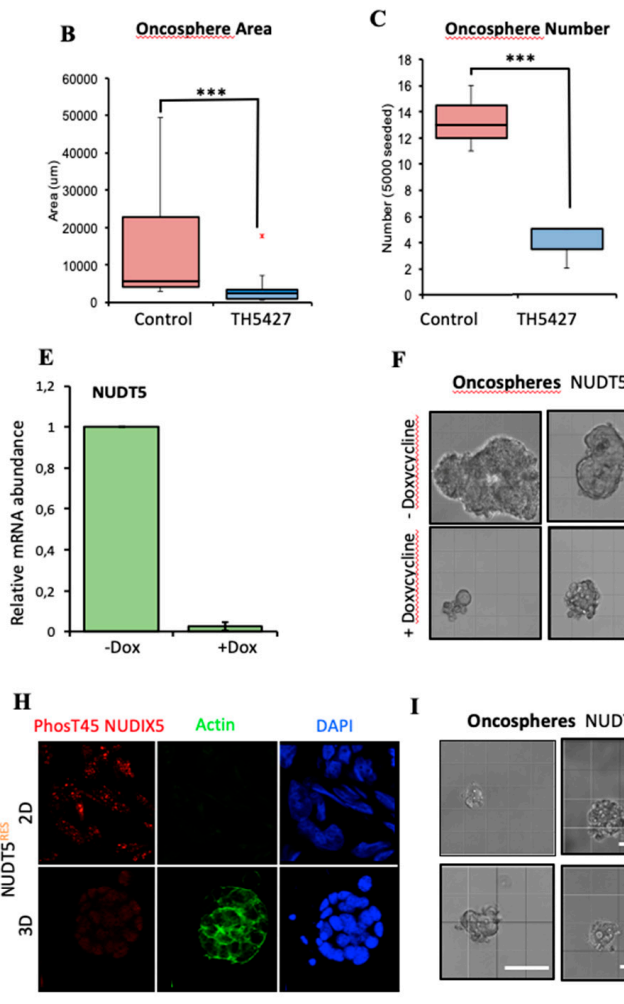

F

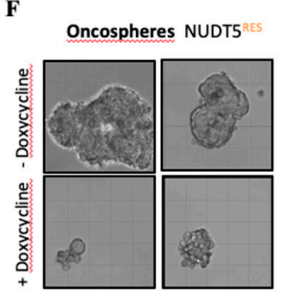

I

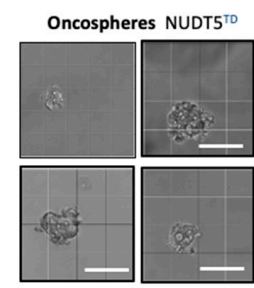

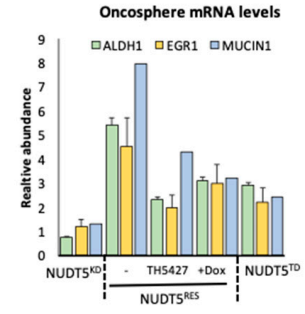

Figure 5. Oncosphere generation is dependent on the ATP-generating activities of NUDT5. (A) Bright field images of oncospheres formed following 5 days in culture in NUDT5 ${ }^{\mathrm{RES}}$ cell lines grown in the absence or presence of $1.5 \mathrm{nM}$ TH5427. Scale bar represents $200 \mu \mathrm{M}$. (B) Quantification of the area of oncospheres formed in NUDT5 ${ }^{\mathrm{RES}}$ cell lines in the presence or absence of TH5427; mean \pm SEM. (C) Quantification of the number of oncospheres formed in NUDT5 ${ }^{R E S}$ cell lines in the presence or absence of TH5427; mean \pm SEM. (D) Stable knock-down and inducible pKAR rescue experimental overview in T47D ${ }^{\mathrm{M}}$ cells. (E) Relative mRNA levels of NUDT5 following the addition of doxycycline to NUDT5 ${ }^{\text {RES }}$ cell lines. (F) Bright field images of oncospheres formed following 5 days in culture in NUDT5 ${ }^{\text {RES }}$ cell lines grown in the presence of doxycycline for $24 \mathrm{~h}$ after seeding. Scale bar represents $200 \mu \mathrm{M}$. (G) Quantification of the area of oncospheres formed in NUDT5 ${ }^{\mathrm{RES}}$ cell lines in the presence or absence of doxycycline, $24 \mathrm{~h}$ after seeding. (H) Immunofluorescent staining of phosphor-T45 NUDT5 in 2D and 3D cell culture conditions. (I) Bright field images of oncospheres formed following 5 days in culture in NUDT5 ${ }^{\mathrm{TD}}$ cell lines. (J) Quantification of second generation self-renewal capacity in NUDT5 ${ }^{\mathrm{RES}}\left( \pm\right.$ TH5427), NUDT5 ${ }^{\mathrm{KD}}$ and NUDT5 ${ }^{\mathrm{TD}}$ cell lines, five days after primary 3D culture disassociation; data represents mean \pm SEM. (K) qRT-PCR gene expression analysis of CSC marker; ALDH and EMT marker; EGFR1 and tumour marker; MUCIN1 in NUDT5 ${ }^{\text {RES }}\left( \pm\right.$ TH5427), NUDT5 ${ }^{\text {KD }}$ and NUDT5 ${ }^{\mathrm{TD}}$ cell lines; data represents mean \pm SEM.

As TH5427 inhibits both the AMP- and ATP-generating activities of NUDT5, and no specific inhibitor targeting only the ATP-generating activities of NUDT5 was available, we took advantage 
of the Tet-Off cassette present within the NUDT5 ${ }^{\text {RES }}$ cells (Figure 5D). Treatment of these cells with doxycycline for $48 \mathrm{~h}$ induced the depletion of the FLAG-NUDT5 rescue mRNA and total protein levels (Figure 5E). NUDT5 ${ }^{\mathrm{RES}}$ cells were grown as oncospheres for 2 days, prior to the doxycycline treatment for an additional 3 days, similar to the NUDT5 ${ }^{\mathrm{KD}}$ cell lines (Figure $3 \mathrm{~A}$ ). This treatment resulted in phenotypically abnormal, significantly fewer and smaller oncospheres in general (Figure 5F,G and Figure S3E,F). The effect of NUDT5 inhibition on oncosphere growth was not limited to cells of breast origin but was observed in multiple cancer cell lines (BT474, HEK293T, U2OS, MNNG-HOS) grown as oncospheres (Figure S3G).

We have previously shown that hormonal induction leads to NUDT5 de-phosphorylation at T45 that results in a catalytic shift in NUDT5 conformation, favouring the ATP-generating enzyme [13]. We hypothesised that in 3D culture conditions, the activity of NUDT5 could also change in a similar way. To explore this possibility, we performed immunofluorescent staining and western blot analysis using a phospho-T45 NUDT5-specific antibody in NUDT5 ${ }^{\text {RES }}$ cell lines grown in 2D and 3D conditions. We found that NUDT5 was phosphorylated at T45 in 2D culture conditions but not in 3D conditions (Figure $5 \mathrm{H}$ ). To test the functional significance of this finding and given the lack of a specific ATP inhibitor, we generated stable cell lines, whereby endogenous NUDT5 was knocked down using shRNA, and rescued with an sh-resistant NUDT5 containing the T45D phosphomimetic mutation, a mutation which we have previously shown to be able to generate AMP but is defective in ATP generation, both in vitro and in vivo [13]. The inability of these cells to form oncospheres (Figure 5I and Figure S3H,I) confirmed the idea that it is the ATP-generating ability that is required for a successful oncosphere generation and maintenance in 3D cultures of breast cancer cells. Moreover, the significant reduction in the self-renewal capacity of these cells in the absence or inhibition of either AMP and ATP, or ATP-only generating activities of NUDT5 indicates a loss of CSC and EMT gene expression changes that are required to maintain growth as oncospheres (Figure 5J), which was confirmed by qRT-PCR for ALDH1, EGFR and MUCIN1 following either knockdown, inhibition or the use of the NUDT5 phosphomimetic mutant (Figure 5K).

2.1.7. NUDT5-Dependent Genes are Required for Oncosphere Growth and Correlate with Poor Cancer Prognosis

The oncosphere expression data (Figure 4C) not only provided insight into known CSC, EMT or tumour markers, but also identified novel NUDT5-dependent genes relevant for oncosphere growth. Therefore, we focused our attention on several of these genes based on the strong activation of their expression in the oncosphere, which was dependent on NUDT5 (Figure 6A). Prostagladin E synthase (PTGES) is known to be associated with an increased risk of breast cancer [46]; focadhesin (FOCAD) is a transmembrane protein of which very little is known, except a putative tumour suppressor role in gliomas [47]; the small GTPase RAB35B has putative oncogenic properties [48] and its inhibition reduces exosome release, tumour growth, CSC and metastasis [49]; the ubiquitin specific peptidase 22 (USP22) has been identified as 1 of 11 known "death from cancer" signature genes [50], promoting lethal tumour progression, being associated with end stage disease and CSC [51,52] and has gained interest as a cancer therapy target [53]. We validated the significant reduction in expression of some of these genes in oncospheres, following the inhibition of NUDT5 by qRT-PCR (Figure 6B). The co-expression correlation of NUDT5 with FOCAD, PTGES, USP22 and RAB35 was further explored using TGCA patient datasets in breast cancer and showed a significant correlation in all cases (Figure 6C). As these genes are regulated by NUDT5 and their expression patterns correlate in patients, we predicted that stratifying patients on the basis of the expression levels of the most NUDT5-dependent genes (FOCAD and USP22) would also predict a poorer patient outcome similar to that observed for NUDT5. This prediction was clearly confirmed in patient datasets (Figure 6D,E). 
A

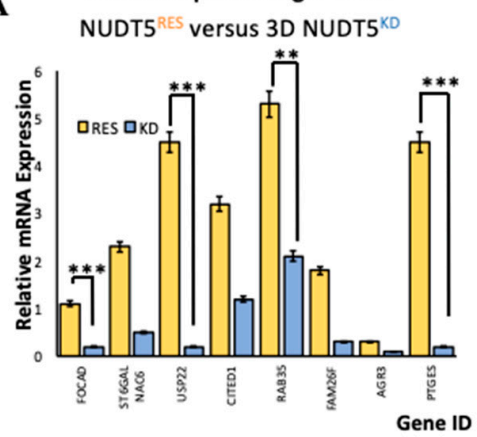

B

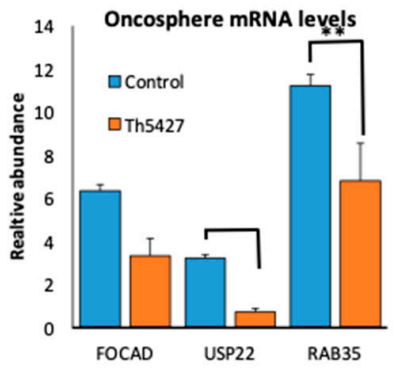

C

Co-expression Analysis Breast BRCA dataset
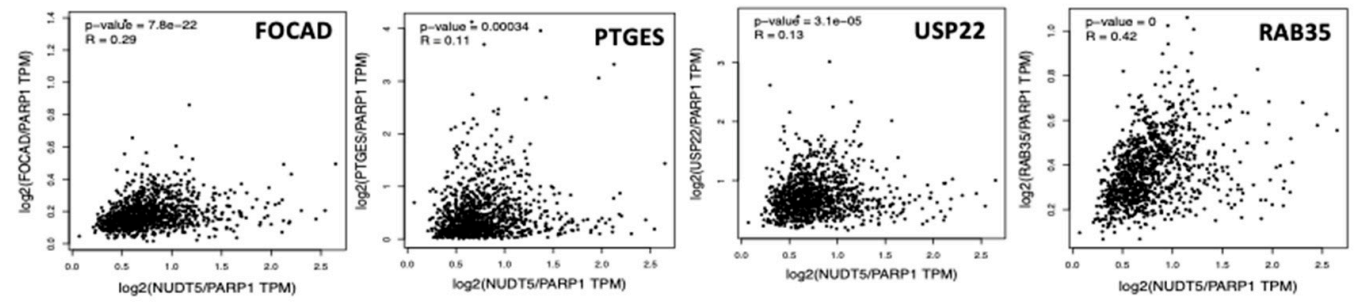

D
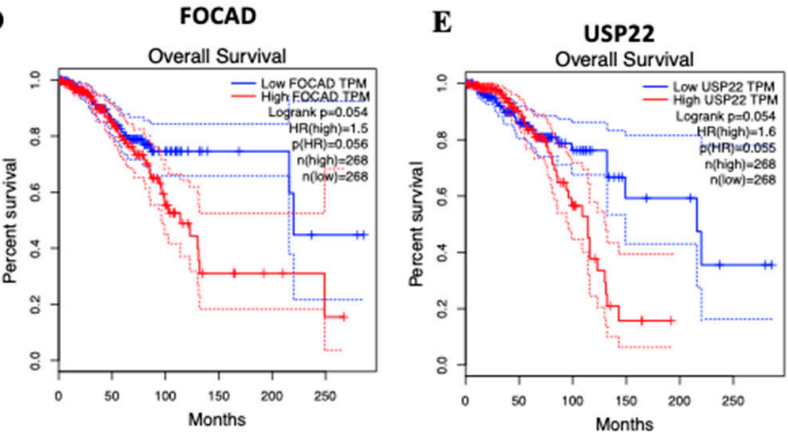

Figure 6. NUDT5 activity induces novel oncogenic drivers in the oncosphere associated with poor prognosis. (A) Relative mRNA expression levels of several genes in NUDT5 ${ }^{\text {RES }}$ versus NUDT5 ${ }^{\mathrm{KD}}$ cell lines in 3D conditions. (B) Expression levels of focadhesin (FOCAD), ubiquitin specific peptidase 22 (USP22) and RAB35 in NUDT5 ${ }^{\mathrm{RES}}$ oncospheres in the presence or absence of TH5427. (C) Co-expression of FOCAD, USP22 and RAB35 mRNA compared to NUDT5 in TGCA breast tumour patient dataset $(n=2435)$. Kaplan Meyer patient data stratifying patients based on the expression levels of FOCAD (D) or USP22 (E).

It remains to be established how the 3D culture conditions lead to de-phosphorylation of NUDT5 and in what form the nuclear synthesis of ATP favours the expression of these set of tumour driver genes. Overall these results support that tumours with elevated expression of these NUDT5-dependent genes are associated with poor prognosis, likely to be explained by the more aggressive cancer phenotype providing novel targets for combinatorial strategies.

\section{Materials and Methods}

\section{1. $2 D$ and $3 D$ Cell Culture}

Transfections were performed using Lipofectamine 2000 (Invitrogen, Carlsbad, California, USA) according to the manufacturer's instructions. For oncosphere generation, cells were seeded at 10,000 cells/well in $2 \mathrm{~mL}$ of DMEM-F12 (supplemented with $20 \mathrm{ng} / \mathrm{mL}$ human EGF and B27) media in lo-bind ultra-low attachment plates. Plates were left un-agitated for 5-6 days and the mammospheres were counted and photographed on an Evos microscope. Mammosphere area was measured using Fiji. 


\subsubsection{Stable Cell Line Generation}

$\mathrm{NUDT5}^{\mathrm{RES}}$ and NUDT5 ${ }^{\mathrm{KD}}$ stable cell lines were generated using the pKAR system [20], as described. Briefly, shRNA targeting endogenous NUDT5 was cloned into pKAR using Bbc1 and Xba1, generating a pKAR-shNUDT5 plasmid (used for generation of NUDT5 ${ }^{\mathrm{KD}}$ cell lines). Subsequently, the coding sequence of an sh-resistant NUDT5 was either wild type NUDT5 ${ }^{\mathrm{RES}}$, or T45D NUDT5 ${ }^{\mathrm{T} 5 \mathrm{D}}$ was generated by PCR out of a myc-NUDT5 vector, flanked with Apa1 and EcoR1. Silent mutations to introduce resistance to the shRNA were introduced with site-directed mutagenesis, and the sequences were cloned in frame upstream of FLAG within PKAR-shNUDT5 to generate and induce knockdown sh-resistant contrast for the generation of NUDT5 rescue cell lines (NUDT5 ${ }^{\text {RES }}$ and NUDT5 ${ }^{45 D}$ ). Individual stable cell clones were selected and expanded following selection with G418 $(100 \mu \mathrm{g} / \mathrm{mL})$.

\subsubsection{Secondary Oncosphere Assays}

The primary mammospheres grown for 5 days were trypsinised for 30 min prior to manual dissociation into a single cell suspension (25-gauge needle). Single cells were re-plated in low-well, low-adherence plates using 1 cell per well. Oncosphere self-renewal was calculated by dividing the number of spheres counted by the number of total cell-containing seeded wells.

\subsubsection{RNA Extraction and RT-PCR}

Total RNA and reverse transcription was carried out according to the manufacturer's instructions (RNAeasy and Superscript II Invitrogen, respectively). Complementary DNA was quantified by qPCR using Roche Lightcycler capillaries (Roche, Basel, Switzerland), as previously described [6]. For each gene product, relative RNA abundance was calculated using the standard curve method and expressed as relative RNA abundance after normalizing against the human GAPDH. Data presented represent the average \pm SEM for at least three independent biological replicates. Primers used for RT-qPCR are available upon request.

\subsubsection{Protein Extract Preparation, Western Blotting}

2D or 3D cell cultures were similarly prepared for protein analysis. Briefly, cells were lysed (1\% $\mathrm{NP40}, 150 \mathrm{mM} \mathrm{NaCl}, 50 \mathrm{mM}$ Tris- $\mathrm{HCl}$ ) and following total protein quantification, equal quantities of cell extract were separated by SDS-PAGE western blot gels and the protein of interest was analysed by western blotting using PARP1- (Cell Signalling technologies, Danvers, Massachusetts, USA) and NUDT5 (Abcam, Cambridge, UK)-specific antibodies.

\subsubsection{Immunofluorescence, Image Acquisition and Analysis}

Two-dimensional or three-dimensional NUDT5 knockdown or knockdown and rescue cultures were fixed in a similar manner with several differences. Two-dimensional cells were grown on round $10 \mathrm{~mm}$ glass coverslips, prior to fixation with $4 \%$ paraformaldehyde in PBS for $5 \mathrm{~min}$, as compared to 3D cultures, which were grown in glass-bottom cell chambers (Lab Tek II, Sigma Aldrich, Sankt Gallen, Switzerland). Following fixation, both types of culture were permeabilized with PBS 0.1\% Triton X-100 (PBS-T) at room temperature for 5 min. Fixed cells were then blocked with 5\% BSA and $0.1 \%$ Triton X-100 in PBS for $20 \mathrm{~min}$ at room temperature and incubated overnight with primary antibodies for phosphor-T45 NUDT5 (generated in-house). Following three washes with PBS-T, samples were incubated with secondary antibodies at a dilution of 1:2000 (AlexaFluor 594 anti-rabbit, Invitrogen-Molecular Probes, Eugene, California, USA) for $1 \mathrm{~h}$ at room temperature, followed by three additional washes with PBS-T. Images of the mounted samples were then acquired with a Leica SP5 confocal microscope using an HC PL 40×/1.4 oil immersion lens using the Leica acquisition software. 


\subsubsection{BrdU Cell Proliferation}

Cell proliferation was assessed using chemiluminescent BrdU assay (Roche, Basel, Switzerland) according to the manufacturer's instructions. Experiments were carried out in triplicate and presented as mean $\pm \mathrm{SEM}$.

\subsubsection{Scratch Wound Healing Assays}

For migration assays, cells were plated out in 24-well plates at a seeding density to ensure confluence within twenty-four hours. Twenty-four hours later, a scratch was made using a $200 \mu \mathrm{L}$ pipette tip. Cell debris was removed by washing, and the images of the gap were taken for the following 3-4 days. Data are represented as relative gap width of three independent experiments carried out in duplicate.

\subsubsection{Colony Formation Assays}

$\mathrm{NUDT}^{\mathrm{RES}}$ and NUDT5 ${ }^{\mathrm{KD}}$ cells were plated out in $10 \mathrm{~cm}$ plates at 1000 cells per plate. Medium was replaced over a 10-days period, allowing colonies to form. Surviving colonies were stained using $5 \%$ crystal violet solution ( $10 \%$ methanol).

\subsection{Bioinformatic Procedures}

\subsubsection{RNA-Seq Data Processing}

The initial samples are available in Table S3. Quality control was evaluated using FastQC [54], and adapter sequences were removed using Trimmomatic [55] with the parameter values: PE, ILLUMINACLIP: TruSeq3-PE-2.fa:2:30:12:1:true LEADING:3 TRAILING:3 MAXINFO:50:0.999 MINLEN:36.

Transcript-level quantification was performed with Kallisto (v. 0.43.0) [56] against the Hg38 version of the genome using $-\mathrm{b}=100$. We discarded two samples (rw_043_01_02_rnaseq and rw_044_01_02_rnaseq) that appeared as outliers in the PCA (Figure S2A) after checking that indeed their distribution of number of counts was much lower (Figure S2).

\subsubsection{Gene Expression Analysis}

Differential expression analysis was performed using the Sleuth package [57] (v. 0.30.0). The DE analysis between $2 \mathrm{D}$ and $3 \mathrm{D}$ was done by aggregating transcript $p$-values into genes using the Lancaster method [58]. We used the likelihood ratio test (lrt) using two different reduced: full models to test for the space and condition effects, respectively, while correcting for the sequencing batch effect. For this test, Sleuth does not return a fold change or equivalent metric; therefore, we calculated a $\log 2$ fold change using the averages across conditions and a pseudocount of $0.01 \log 2\left(\mathrm{tpm} \_w t+0.01 / \mathrm{tpm} \_k d+0.01\right)$.

The comparisons within spaces (2D_wt vs. 2D_kd and 3D_wt vs. 3D_kd) were done using the Wald test at the transcript level. We used a single variable with four values (2D_wt, 2D_kd, 3D_wt, $3 \mathrm{D} \_\mathrm{kd}$ ) and generated contrasts to test for specific comparisons while correcting for the sequencing batch effect.

Enriched gene expression signatures associated with EMT and the corresponding global prioritization scores shown in Figure 2D were obtained from dbEMT online resource [59].

\subsubsection{Gene Ontology Analysis}

GO biological process (BP), molecular function (MF), reactome pathway and CORUM complex analysis was performed using the online analysis database, Enrichr [60]. Enriched medical subject headings $(\mathrm{MeSH})$ were calculated using the SEEK Princeton database. 


\subsubsection{Kaplan Meyer Survival Analysis}

Kaplan Meyer stratifying of patients based on gene expression levels of NUDT5 and USP22 was performed using the PrognoScan database, GEPIA (Gene Expression Profiling Interactive Analysis) [61] and Human protein Atlas [62]. NUDT5 overexpression was considered significant containing a corrected $p$-value of less than 0.05 , the number of patients considered in each cohort tested is given on the graphs.

\section{Conclusions}

The work presented here shed light onto the mechanism by which elevated levels of NUDT5 observed in cancer patients is predictive of a poor outcome and prognosis (Figure S4). We have shown that elevated levels of NUDT5 and, specifically, ATP enzymatic activity are essential in driving the expression of known CSC and EMT genes, as well as novel tumour drivers detected using the 3D oncosphere model (Figure S5). The NUDT5-dependent expression of known EMT and CSC genes and of new cancer driver genes (FOCAD and USP22), which also predict a poorer overall outcome in patient datasets, strongly indicate that any future drug discovery focusing on an ATP-specific inhibitor of NUDT5 would be potentially beneficial for the treatment of cancers, including breast and ovarian cancer; in reducing side effects; improving patient health and lifting economic burden.

Supplementary Materials: The following are available online at http://www.mdpi.com/2072-6694/11/9/1337/s1, Figure S1: NUDT5 is indicative of poor prognosis and aggressive cancer growth; Figure S2: Analysis of the gene expression changes in 3D compared to 2D culture conditions; Figure S3: Characterisation of the gene expression changes dependent on NUDT5 in 3D cell culture; Figure S4: Model for the role of NUDT5 in tumour progression; Figure S5: Model for the driving role of NUDT5 expression metastasis. Table S1: Abbreviations for TGCA cancer types; Table S2: IDs from the Human Protein Atlas; Table S3: RNA-seq sample information; Table S4: Published gene expression signatures linked to 3D culture growth; Table S5: Protein complex alterations in 3D culture; Table S6: Gene ontology biological processes altered in 2D to 3D cell culture; Table S7: Reactome pathways' 2D to 3D transition; Table S8: Kegg pathways' 2D to 3D transition; Table S9: Full transcription factor binding sites motifs.

Author Contributions: Conceptualization, R.H.G.W. and M.B.; methodology, R.H.G.W., K.E.P. and M.B.; formal analysis (bioinformatics), J.L.V.-C. and J.C.-C.; investigation, K.E.P., F.P., A.L., R.H.G.W.; writing-original draft preparation, R.H.G.W. and M.B.; writing-review and editing, R.H.G.W. and M.B.; visualisation, R.H.G.W.; supervision, R.H.G.W. and M.B.

Funding: The experimental work mentioned was supported by European Research Council (Project "4D Genome" 609989), the Ministerio de Economía y Competitividad (Project G62426937) and the Generalitat de Catalunya (Project AGAUR SGR 575).

Acknowledgments: We thank the other members of the Miguel Beato lab for their insight and advice throughout the preparation of the manuscript, especially the work done by Bahar Deniz and Sina Schmidt during their training periods.

Conflicts of Interest: The authors declare no conflict of interest.

\section{References}

1. Lambert, A.W.; Pattabiraman, D.R.; Weinberg, R.A. Emerging Biological Principles of Metastasis. Cell 2017, 168, 670-691. [CrossRef] [PubMed]

2. Teng, Y.D.; Wang, L.; Kabatas, S.; Ulrich, H.; Zafonte, R.D. Cancer Stem Cells or Tumor Survival Cells? Stem Cells Dev. 2018, 27, 1466-1478. [CrossRef] [PubMed]

3. Nunes, T.; Hamdan, D.; Leboeuf, C.; El Bouchtaoui, M.; Gapihan, G.; Nguyen, T.T.; Meles, S.; Angeli, E.; Ratajczak, P.; Lu, H.; et al. Targeting Cancer Stem Cells to Overcome Chemoresistance. Int. J. Mol. Sci. 2018, 19, 4036. [CrossRef] [PubMed]

4. Palomeras, S.; Ruiz-Martinez, S.; Puig, T. Targeting Breast Cancer Stem Cells to Overcome Treatment Resistance. Molecules 2018, 23, 2193. [CrossRef] [PubMed]

5. Doherty, M.R.; Smigiel, J.M.; Junk, D.J.; Jackson, M.W. Cancer Stem Cell Plasticity Drives Therapeutic Resistance. Cancers 2016, 8, 8. [CrossRef] [PubMed] 
6. Wright, R.H.; Castellano, G.; Bonet, J.; Le Dily, F.; Font-Mateu, J.; Ballare, C.; Nacht, A.S.; Soronellas, D.; Oliva, B.; Beato, M. CDK2-dependent activation of PARP-1 is required for hormonal gene regulation in breast cancer cells. Genes Dev. 2012, 26, 1972-1983. [CrossRef] [PubMed]

7. Wright, R.H.; Beato, M. PARty promoters: Hormone-dependent gene regulation requires CDK2 activation of PARP1. Cell Cycle 2012, 11, 4291-4293. [CrossRef] [PubMed]

8. Fatokun, A.A.; Dawson, V.L.; Dawson, T.M. Parthanatos: Mitochondrial-linked mechanisms and therapeutic opportunities. Br. J. Pharmacol. 2014, 171, 2000-2016. [CrossRef]

9. Pascal, J.M. The comings and goings of PARP-1 in response to DNA damage. DNA Repair (Amst) 2018, 71, 177-182. [CrossRef]

10. Hanzlikova, H.; Kalasova, I.; Demin, A.A.; Pennicott, L.E.; Cihlarova, Z.; Caldecott, K.W. The Importance of Poly(ADP-Ribose) Polymerase as a Sensor of Unligated Okazaki Fragments during DNA Replication. Mol. Cell 2018, 71, 319-331.e313. [CrossRef]

11. Ray Chaudhuri, A.; Nussenzweig, A. The multifaceted roles of PARP1 in DNA repair and chromatin remodelling. Nat. Rev. Mol. Cell Biol. 2017, 18, 610-621. [CrossRef] [PubMed]

12. Zha, M.; Zhong, C.; Peng, Y.; Hu, H.; Ding, J. Crystal structures of human NUDT5 reveal insights into the structural basis of the substrate specificity. J. Mol. Biol. 2006, 364, 1021-1033. [CrossRef] [PubMed]

13. Wright, R.H.; Lioutas, A.; Le Dily, F.; Soronellas, D.; Pohl, A.; Bonet, J.; Nacht, A.S.; Samino, S.; Font-Mateu, J.; Vicent, G.P.; et al. ADP-ribose-derived nuclear ATP synthesis by NUDIX5 is required for chromatin remodeling. Science 2016, 352, 1221-1225. [CrossRef] [PubMed]

14. Ishiguro, T.; Ohata, H.; Sato, A.; Yamawaki, K.; Enomoto, T.; Okamoto, K. Tumor-derived spheroids: Relevance to cancer stem cells and clinical applications. Cancer Sci. 2017, 108, 283-289. [CrossRef] [PubMed]

15. He, J.; Xiong, L.; Li, Q.; Lin, L.; Miao, X.; Yan, S.; Hong, Z.; Yang, L.; Wen, Y.; Deng, X. 3D modeling of cancer stem cell niche. Oncotarget 2018, 9, 1326-1345. [CrossRef] [PubMed]

16. Forte, E.; Chimenti, I.; Rosa, P.; Angelini, F.; Pagano, F.; Calogero, A.; Giacomello, A.; Messina, E. EMT/MET at the Crossroad of Stemness, Regeneration and Oncogenesis: The Ying-Yang Equilibrium Recapitulated in Cell Spheroids. Cancers 2017, 9, 98. [CrossRef]

17. Morrison, B.J.; Hastie, M.L.; Grewal, Y.S.; Bruce, Z.C.; Schmidt, C.; Reynolds, B.A.; Gorman, J.J.; Lopez, J.A. Proteomic comparison of mcf-7 tumoursphere and monolayer cultures. PLoS ONE 2012, 7, e52692. [CrossRef] [PubMed]

18. Hoarau-Vechot, J.; Rafii, A.; Touboul, C.; Pasquier, J. Halfway between 2D and Animal Models: Are 3D Cultures the Ideal Tool to Study Cancer-Microenvironment Interactions? Int. J. Mol. Sci. 2018, $19,181$. [CrossRef]

19. Langhans, S.A. Three-Dimensional in Vitro Cell Culture Models in Drug Discovery and Drug Repositioning. Front. Pharmacol. 2018, 9, 6. [CrossRef]

20. Ma, H.T.; On, K.F.; Tsang, Y.H.; Poon, R.Y. An inducible system for expression and validation of the specificity of short hairpin RNA in mammalian cells. Nucleic Acids Res. 2007, 35, e22. [CrossRef]

21. Callari, M.; Guffanti, A.; Solda, G.; Merlino, G.; Fina, E.; Brini, E.; Moles, A.; Cappelletti, V.; Daidone, M.G. In-depth characterization of breast cancer tumor-promoting cell transcriptome by RNA sequencing and microarrays. Oncotarget 2016, 7, 976-994. [CrossRef] [PubMed]

22. Al-Hajj, M.; Wicha, M.S.; Benito-Hernandez, A.; Morrison, S.J.; Clarke, M.F. Prospective identification of tumorigenic breast cancer cells. Proc. Natl. Acad. Sci. USA 2003, 100, 3983-3988. [CrossRef] [PubMed]

23. Dontu, G.; Abdallah, W.M.; Foley, J.M.; Jackson, K.W.; Clarke, M.F.; Kawamura, M.J.; Wicha, M.S. In vitro propagation and transcriptional profiling of human mammary stem/progenitor cells. Genes Dev. 2003, 17, 1253-1270. [CrossRef] [PubMed]

24. Ballesta, A.M.; Molina, R.; Filella, X.; Jo, J.; Gimenez, N. Carcinoembryonic antigen in staging and follow-up of patients with solid tumors. Tumour. Biol. 1995, 16, 32-41. [CrossRef] [PubMed]

25. Gebauer, F.; Wicklein, D.; Horst, J.; Sundermann, P.; Maar, H.; Streichert, T.; Tachezy, M.; Izbicki, J.R.; Bockhorn, M.; Schumacher, U. Carcinoembryonic antigen-related cell adhesion molecules (CEACAM) 1, 5 and 6 as biomarkers in pancreatic cancer. PLoS ONE 2014, 9, e113023. [CrossRef]

26. Beauchemin, N.; Arabzadeh, A. Carcinoembryonic antigen-related cell adhesion molecules (CEACAMs) in cancer progression and metastasis. Cancer Metastasis Rev. 2013, 32, 643-671. [CrossRef] [PubMed]

27. Johnson, B.; Mahadevan, D. Emerging Role and Targeting of Carcinoembryonic Antigen-related Cell Adhesion Molecule 6 (CEACAM6) in Human Malignancies. Clin. Cancer Drugs 2015, 2, 100-111. [CrossRef] 
28. Meng, Q.; Shi, S.; Liang, C.; Liang, D.; Xu, W.; Ji, S.; Zhang, B.; Ni, Q.; Xu, J.; Yu, X. Diagnostic and prognostic value of carcinoembryonic antigen in pancreatic cancer: A systematic review and meta-analysis. Onco Targets Ther. 2017, 10, 4591-4598. [CrossRef] [PubMed]

29. Lee, J.H.; Lee, S.W. The Roles of Carcinoembryonic Antigen in Liver Metastasis and Therapeutic Approaches. Gastroenterol. Res. Pract. 2017, 2017, 7521987. [CrossRef]

30. Borras, G.; Molina, R.; Xercavins, J.; Ballesta, A.; Iglesias, J. Tumor antigens CA 19.9, CA 125, and CEA in carcinoma of the uterine cervix. Gynecol. Oncol. 1995, 57, 205-211. [CrossRef]

31. Powell, E.; Shao, J.; Picon, H.M.; Bristow, C.; Ge, Z.; Peoples, M.; Robinson, F.; Jeter-Jones, S.L.; Schlosberg, C.; Grzeskowiak, C.L.; et al. A functional genomic screen in vivo identifies CEACAM5 as a clinically relevant driver of breast cancer metastasis. NPJ Breast Cancer 2018, 4, 9. [CrossRef] [PubMed]

32. Jing, X.; Liang, H.; Hao, C.; Yang, X.; Cui, X. Overexpression of MUC1 predicts poor prognosis in patients with breast cancer. Oncol. Rep. 2019, 41, 801-810. [CrossRef] [PubMed]

33. Bell, R.; Barraclough, R.; Vasieva, O. Gene Expression Meta-Analysis of Potential Metastatic Breast Cancer Markers. Curr. Mol. Med. 2017, 17, 200-210. [CrossRef] [PubMed]

34. Al Masri, A.; Gendler, S.J. Muc1 affects c-Src signaling in PyV MT-induced mammary tumorigenesis. Oncogene 2005, 24, 5799-5808. [CrossRef] [PubMed]

35. Vizcaino, C.; Mansilla, S.; Portugal, J. Sp1 transcription factor: A long-standing target in cancer chemotherapy. Pharmacol. Ther. 2015, 152, 111-124. [CrossRef] [PubMed]

36. Gaboli, M.; Kotsi, P.A.; Gurrieri, C.; Cattoretti, G.; Ronchetti, S.; Cordon-Cardo, C.; Broxmeyer, H.E.; Hromas, R.; Pandolfi, P.P. Mzf1 controls cell proliferation and tumorigenesis. Genes Dev. 2001, 15, 1625-1630. [CrossRef] [PubMed]

37. Nygaard, M.; Terkelsen, T.; Vidas Olsen, A.; Sora, V.; Salamanca Viloria, J.; Rizza, F.; Bergstrand-Poulsen, S.; Di Marco, M.; Vistesen, M.; Tiberti, M.; et al. The Mutational Landscape of the Oncogenic MZF1 SCAN Domain in Cancer. Front. Mol. Biosci. 2016, 3, 78. [CrossRef]

38. Mollen, E.W.J.; Ient, J.; Tjan-Heijnen, V.C.G.; Boersma, L.J.; Miele, L.; Smidt, M.L.; Vooijs, M. Moving Breast Cancer Therapy up a Notch. Front. Oncol. 2018, 8, 518. [CrossRef]

39. Farnie, G.; Willan, P.M.; Clarke, R.B.; Bundred, N.J. Combined inhibition of ErbB1/2 and Notch receptors effectively targets breast ductal carcinoma in situ (DCIS) stem/progenitor cell activity regardless of ErbB2 status. PLoS ONE 2013, 8, e56840. [CrossRef]

40. Cochrane, C.R.; Szczepny, A.; Watkins, D.N.; Cain, J.E. Hedgehog Signaling in the Maintenance of Cancer Stem Cells. Cancers 2015, 7, 1554-1585. [CrossRef]

41. Monkkonen, T.; Lewis, M.T. New paradigms for the Hedgehog signaling network in mammary gland development and breast Cancer. Biochim. Biophys. Acta Rev. Cancer 2017, 1868, 315-332. [CrossRef] [PubMed]

42. Grudzien, P.; Lo, S.; Albain, K.S.; Robinson, P.; Rajan, P.; Strack, P.R.; Golde, T.E.; Miele, L.; Foreman, K.E. Inhibition of Notch signaling reduces the stem-like population of breast cancer cells and prevents mammosphere formation. Anticancer Res. 2010, 30, 3853-3867. [PubMed]

43. Liu, S.; Dontu, G.; Mantle, I.D.; Patel, S.; Ahn, N.S.; Jackson, K.W.; Suri, P.; Wicha, M.S. Hedgehog signaling and Bmi-1 regulate self-renewal of normal and malignant human mammary stem cells. Cancer Res. 2006, 66, 6063-6071. [CrossRef] [PubMed]

44. Wright, R.H.; Fernandez-Fuentes, N.; Oliva, B.; Beato, M. Insight into the machinery that oils chromatin dynamics. Nucleus 2016, 7, 532-539. [CrossRef] [PubMed]

45. Page, B.D.G.; Valerie, N.C.K.; Wright, R.H.G.; Wallner, O.; Isaksson, R.; Carter, M.; Rudd, S.G.; Loseva, O.; Jemth, A.S.; Almlof, I.; et al. Targeted NUDT5 inhibitors block hormone signaling in breast cancer cells. Nat. Commun. 2018, 9, 250. [CrossRef]

46. Mehrotra, S.; Morimiya, A.; Agarwal, B.; Konger, R.; Badve, S. Microsomal prostaglandin E2 synthase-1 in breast cancer: A potential target for therapy. J. Pathol. 2006, 208, 356-363. [CrossRef] [PubMed]

47. Brockschmidt, A.; Trost, D.; Peterziel, H.; Zimmermann, K.; Ehrler, M.; Grassmann, H.; Pfenning, P.N.; Waha, A.; Wohlleber, D.; Brockschmidt, F.F.; et al. KIAA1797/FOCAD encodes a novel focal adhesion protein with tumour suppressor function in gliomas. Brain 2012, 135, 1027-1041. [CrossRef]

48. Wheeler, D.B.; Zoncu, R.; Root, D.E.; Sabatini, D.M.; Sawyers, C.L. Identification of an oncogenic RAB protein. Science 2015, 350, 211-217. [CrossRef] 
49. Villagomez, F.R.; Medina-Contreras, O.; Cerna-Cortes, J.F.; Patino-Lopez, G. The role of the oncogenic Rab35 in cancer invasion, metastasis, and immune evasion, especially in leukemia. Small GTPases 2018, 1-12. [CrossRef]

50. Glinsky, G.V. Death-from-cancer signatures and stem cell contribution to metastatic cancer. Cell Cycle 2005, 4, 1171-1175. [CrossRef]

51. Schrecengost, R.S.; Dean, J.L.; Goodwin, J.F.; Schiewer, M.J.; Urban, M.W.; Stanek, T.J.; Sussman, R.T.; Hicks, J.L.; Birbe, R.C.; Draganova-Tacheva, R.A.; et al. USP22 regulates oncogenic signaling pathways to drive lethal cancer progression. Cancer Res. 2014, 74, 272-286. [CrossRef] [PubMed]

52. Zhang, X.Y.; Varthi, M.; Sykes, S.M.; Phillips, C.; Warzecha, C.; Zhu, W.; Wyce, A.; Thorne, A.W.; Berger, S.L.; McMahon, S.B. The putative cancer stem cell marker USP22 is a subunit of the human SAGA complex required for activated transcription and cell-cycle progression. Mol. Cell 2008, 29, 102-111. [CrossRef] [PubMed]

53. Yun, X.; Zhang, K.; Wang, J.; Pangeni, R.P.; Yang, L.; Bonner, M.; Wu, J.; Wang, J.; Nardi, I.K.; Gao, M.; et al. Targeting USP22 Suppresses Tumorigenicity and Enhances Cisplatin Sensitivity Through ALDH1A3 Downregulation in Cancer-Initiating Cells from Lung Adenocarcinoma. Mol. Cancer Res. 2018, 16, 1161-1171. [CrossRef] [PubMed]

54. Wingett, S.W.; Andrews, S. FastQ Screen: A tool for multi-genome mapping and quality control. F1000Research 2018, 7, 1338. [CrossRef] [PubMed]

55. Bolger, A.M.; Lohse, M.; Usadel, B. Trimmomatic: A flexible trimmer for Illumina sequence data. Bioinformatics 2014, 1, 2114-2120. [CrossRef]

56. Bray, N.; Pimentel, H.; Melsted, P.; Pachter, L. Near-optimal probabilistic RNA-seq quantification. Nat. Biotechnol. 2016, 34, 525-527. [CrossRef] [PubMed]

57. Pimentel, H.; Bray, N.L.; Puente, S.; Melsted, P.; Pachter, L. Differential analysis of RNA-seq incorporating quantification uncertainty. Nat. Methods 2017, 14, 687-690. [CrossRef]

58. Yi, L.; Pimentel, H.; Bray, N.L.; Pachter, L. Gene-level differential analysis at transcript-level resolution. Genome Biol. 2018, 19, 53. [CrossRef]

59. Zhao, M.; Kong, L.; Liu, Y.; Qu, H. dbEMT: An epithelial-mesenchymal transition associated gene resource. Sci. Rep. 2015, 5, 11459. [CrossRef]

60. Kuleshov, M.V.; Jones, M.R.; Rouillard, A.D.; Fernandez, N.F.; Duan, Q.; Wang, Z.; Koplev, S.; Jenkins, S.L.; Jagodnik, K.M.; Lachmann, A.; et al. Enrichr: A comprehensive gene set enrichment analysis web server 2016 update. Nucleic Acids Res. 2016, 44, W90-W97. [CrossRef]

61. Tang, Z.; Li, C.; Kang, B.; Gao, G.; Li, C.; Zhang, Z. GEPIA: A web server for cancer and normal gene expression profiling and interactive analyses. Nuc. Acid. Res. 2017, 45, W98-W102. [CrossRef] [PubMed]

62. Uhlen, M.; Zhang, C.; Lee, S.; Sjöstedt, E.; Fagerberg, L.; Bidkhori, G.; Benfeitas, R.; Arif, M.; Liu, Z.; Edfors, F.; et al. A pathology atlas of the human cancer transcriptome. Science 2017, 6352, eaan2507. [CrossRef] [PubMed]

(C) 2019 by the authors. Licensee MDPI, Basel, Switzerland. This article is an open access article distributed under the terms and conditions of the Creative Commons Attribution (CC BY) license (http://creativecommons.org/licenses/by/4.0/). 